\title{
Clustered PV Inverters in LV Networks: An Overview of Impacts and Comparison of Voltage Control Strategies
}

\author{
Erhan Demirok, Dezso Sera, Student Member, IEEE, Remus Teodorescu, Senior Member, IEEE, \\ Pedro Rodriguez, and U. Borup, Member, IEEE
}

\begin{abstract}
High penetration of photovoltaic (PV) inverters in low voltage (LV) distribution network challenges the voltage stability due to interaction between multiple inverters and grid. As the main objective is to provide more power injection from VSC-based PV inverters, grid stability, reliability and power quality must be maintained or improved by adding cooperative control features to the grid-connected inverters. This paper first gives an overview of bilateral impacts between multiple distributed generations (DG) and grid. Regarding of these impacts, recent advances in static grid voltage support functionalities to increase penetration level are compared considering voltage rise limitation. Steady-state simulation study is realized in PSCAD/EMTDC and the results are discussed in terms of total generation efficiency.
\end{abstract}

Index Terms-Distributed generation (DG), LV network, power curtailment, $\mathrm{PV}$ inverter, reactive power control, voltage control.

\section{INTRODUCTION}

$\mathrm{P}$ $\mathrm{V}$ installations can mainly be categorized into two types of applications depending on generation capacity and installation area: Solar parks, clustered PV. High-power, centralized inverters are usually interfaced to medium voltage (MV) network in solar parks up to total capacity of tens of MWp ratings [1]-[5]. Clustered PV systems are highly distributed, connected to $\mathrm{LV}$ networks in small rated PV capacities (from a few $\mathrm{kWp}$ to tens of $\mathrm{kWp}$ ) and generally installed on the rooftops [4], [6]-[8]. Each building has own PV inverters and distribution network usually exhibits strong grid characteristics in the residential urban area. In the case of high PV penetration, the network voltage can increase to unacceptable level when active power generation is higher than load demand. This paper deals with the second case which multiple inverters interact with residential LV distribution network.

Up to the present time, the function of distributed PV inverters was to inject current synchronized with grid where

E. Demirok, D. Sera, and R. Teodorescu are with the Section of Power Electronics Systems, Institute of Energy Technology, Aalborg University, 9220 Aalborg, Denmark (e-mail: ede@iet.aau.dk; des@iet.aau.dk; ret@iet.aau.dk).

P. Rodriguez is with the Department of Electrical Engineering, Universitat Politecnica de Catalunya, 08222 Terrassa, Spain (e-mail: prodriguez@ee.upc.edu).

U. Borup is with Danfoss Solar Inverters A/S, Jyllandsgade 28 DK-6400 Sønderborg, Denmark (e-mail: uffe.borup@danfoss.com) its magnitude depends on available de power and its phase is adjusted in such a way that unity power factor is achieved. Besides active power injection, additional functions can be added as ancillary services like low order selective harmonic compensation [9], anti-islanding detection [10], [11], lowvoltage ride-through [12] and voltage unbalance correction [12], [13] by improving grid interaction capabilities of inverters. But these multifunctional features are not enough to avoid voltage rise phenomena which is limited by utility standards [14], [15] at the point of common couplings. Further on, as opposed to $\mathrm{HV}$ and MV networks, LV distribution networks which are mostly designed as radial configuration show resistive impedance characteristics [16]. Moreover, instead of on-load tap changer (OLTC) transformers [17], offload tap changers for $\mathrm{MV} / \mathrm{LV}$ distribution transformers are widely used in the substations and single-phase loads are dominantly distributed along the network [18]. Accordingly, control strategies of LV grid-interfaced PV inverters and relevant grid requirements differ from MV grid-interfaced inverters where grid voltage support features are included.

This paper discusses some reported control strategies of LV grid-interfaced inverters in order to keep network voltage in a defined range without violating over voltage values due to power injection into the grid and improve penetration level. Firstly, arising interaction problems between distributed inverters and LV network are briefly defined in section II. Voltage control strategies are investigated and compared in section III. A benchmark LV residential feeder with PV inverters is modeled by using PSCAD/EMTDC and simulation results are given in section IV by implanting different voltage control strategies. In section $\mathrm{V}$, the paper is concluded with some remarks for future work in the area of control of grid interactive multiple inverters in LV networks.

\section{BILATERAL IMPACTS BETWEEN MULTIPLE PV INVERTERS \& LV NETWORK}

\section{A. Voltage Rise}

One of the impacts of high number of distributed PV inverters along LV network is voltage increase. Second column of Fig. 1 depicts the typical voltage profile when each $\mathrm{PV}$ inverter injects active power under maximum nominal and light loads. Since off-load tap of LV distribution transformer is already adjusted by estimating voltage drop with maximum nominal load, only minimum load or light load condition 
should be estimated to investigate voltage rise. Possible solutions to the voltage rise problem can be mainly categorized as follows [19]:

- Output power limitation

- Reactive power control capability

- Storage system

- DVR, STATCOM, SVC addition to the network
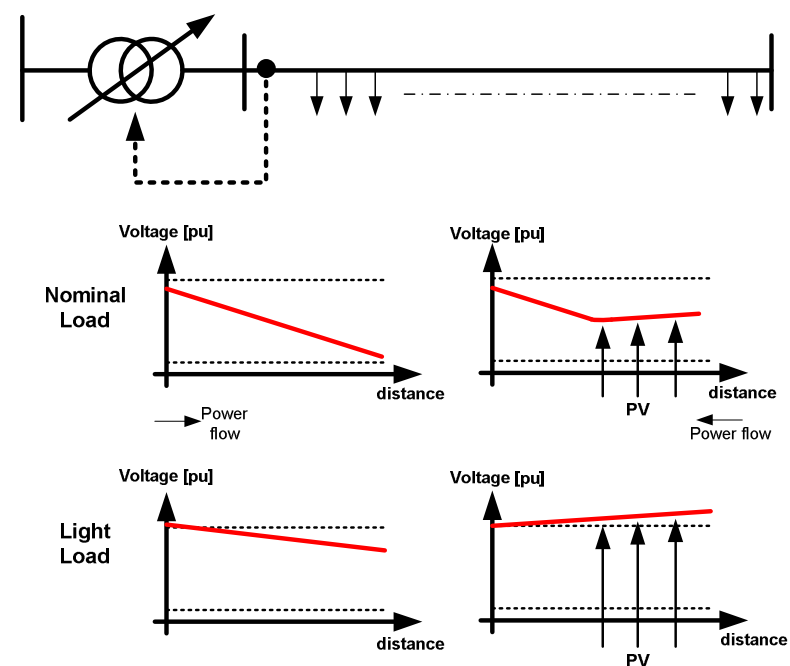

Fig. 1. Typical voltage profile in a LV feeder. Second column shows the voltage profile with PV inverters.

\section{B. Harmonics}

From the harmonics point of view, each inverter which is interfaced to the public LV network is still considered as an electronic equipment [20]. Clustered PV inverters might trigger a parallel resonance due to interaction between equivalent line inductance, capacitance of residential units, and injected harmonic currents. Resonance frequency for residential LV network might be decreased to the fifth harmonics level depending on number of residential units, inverter output filter capacitance and line impedance [21]. Operation of LV grid-interfaced inverters might be affected by background voltage distortions existing in the network if grid synchronization and current controller structures of inverters are sensitive to grid voltage [21].

As highlighted in [22], inverters can show different characteristics against to background voltage distortion. Depending on phase angle between injected current and corresponding grid voltage harmonic, distributed inverters might attenuate, amplify or neutralize the grid voltage harmonics. Calculation of absolute current harmonics amplitude with pure sinusoidal grid voltage is inadequate to perform in real grid with multiple PV inverters.

Besides power injection, each inverter can be considered as a potential active filter distributed along LV network if voltage harmonic attenuation is achieved. In [23], a strategy is developed to share harmonic loading between multiple inverters by using droop characteristics between harmonic conductance and harmonic VAR (G-H).

\section{DC Injections}

DC current circulating in the network might saturate gridinterfaced magnetic components; generate pulsating torques, vibration and additional heating on electrical machines. Further on, half-cycle saturation causes reactive power loss in distribution transformers due to orthogonality of half-cycle current and voltage vector [24]. Cyclo-converters and transformerless inverters are potential risks of dc current injection into LV network [25], [26]. While isolation transformer is obligatory only in Spain to mitigate dc injection problem [27], in other countries like Germany, UK, Japan and Australia, a de detection device with disconnection feature for transformerless inverters is required and maximum allowable dc current varies between 0.5-1percent of inverter rated current by various national standards [28].

\section{Unintentional Islanding}

When power system is disconnected from a downstream local network due to maintenance purpose or unintentional disconnection (equipment failures), grid-interfaced $\mathrm{PV}$ inverters might keep on power injection into isolated part. Since the most inverters are based on current controlled VSC, voltage/frequency stability of islanded network becomes degraded. Potential risks also arise for line workers [26]. Inverters shall either operate as voltage sources (assuming having enough reserved power for a short-time operation) or be shut down after islanding. For this reason, islanding condition shall be detected correctly [29], [30].

Islanding detection methods are mainly implemented in two ways assuming no communication link is installed: Passive and active methods. While only local measurements are employed to determine grid condition for passive methods, current or power injections by disturbing grid without loss of power quality are required in the case of active methods. In [31], passive methods are investigated as over/under voltage (OUV), over/under frequency (OUF), voltage harmonic and phase monitoring. There exists current harmonics injection method, active/reactive power variation method, capacitor connection method, Sandia voltage shift (SVS), slip-mode frequency shift (SMS) active methods by perturbing and measuring point of common coupling (PCC) voltage [32].

\section{E. Voltage Dips and Unbalance}

Voltage dip is defined as reduction in rms voltage between $1 \%$ and $90 \%$ of nominal value with duration between half cycle to several seconds [14], [33]. It causes sensitive equipments failed to function properly. Short circuits (in HV, MV and LV networks) and high load start-ups are the main reasons of voltage dip. Since short circuit can be occurred in a symmetrical or unsymmetrical manner depending on fault type, voltage dips can also be in various types [34].

Although the depth of a voltage dip depends on fault location, network impedance and short circuit power of $\mathrm{MV} / \mathrm{LV}$ transformers [35], grid interfaced multiple inverters which have voltage support features can contribute to mitigation of voltage dips [12], [36]-[39]. 


\section{F. Grid Impedance Variation}

Grid interfaced inverters require output filter to attenuate low and high frequency components and coupling to the grid. LCL filters have better stability and cost performance than L/LC/LLC filters with lower grid harmonic sensitivity [40][42]. Active or passive methods are also required to damp resonance frequency of LCL filter according to grid impedance.

In [43] and [44], it is shown that if inverter with $\mathrm{P}+\mathrm{Resonant}$ controller [9] and LCL filter is designed with respect to stiff grid condition but it is connected to weak grid (higher grid inductance), then low frequency resonant controllers (at $5^{\text {th }}$ and $7^{\text {th }}$ ) might be out of range of current controller bandwidth. Increasing proportional gain to extend bandwidth might cause closed-loop system be unstable. In similar way, at high frequency range, passive and active damping methods designed with respect to strong grid condition become inefficient under weak grid condition. Accordingly grid impedance information can increase efficiency of active damping by varying resonance damping of poles and zeros.

\section{VOLTAGE CONTROL STRATEGIES}

In this section, the most used voltage control strategies as solutions to the network voltage rise problem are given regarding that no storage system is installed in the clustered PV system. Only local PCC measurements are utilized.

\section{A. Power Curtailment}

When inverter output terminal voltage reaches to over voltage level, output active power is limited by forcing operation from the maximum power point towards the open circuit voltage of PV panel. If the PCC terminal voltage still maintains overvoltage issue $\left(U_{\lim i t}=U_{n}+10 \% U_{n}\right)$, then the inverter finally ceases power transfer into grid [45], [46].

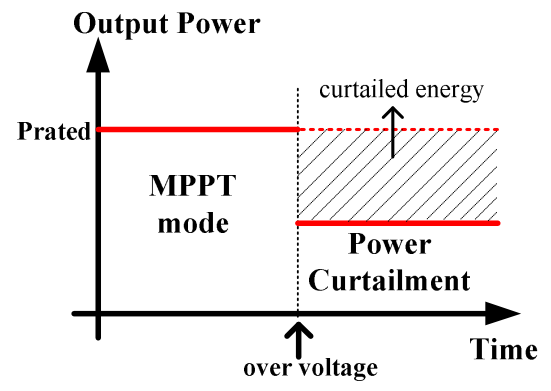

Fig. 2. Power curtailment after over voltage condition.

\section{B. Reactive Power Support}

By means of providing control of reactive power injection/absorption, distributed PV based VSCs can contribute to network voltage as both dynamically and statically. Only static voltage support is considered in this paper regarding of voltage rise problem.

As shown in Fig. 3, reactive power is absorbed (inductive loading) from the network to make local PCC voltage lower.
In the event that local PCC voltage still keeps on overvoltage situation, power curtailment strategy can be put into use [47]. In this case, additional inverter capacity is required to be able to provide reactive power flow. $17.64-\%$ over-rating extends the operation range of inverter between 0.85 lagging and 0.85 leading power factor.

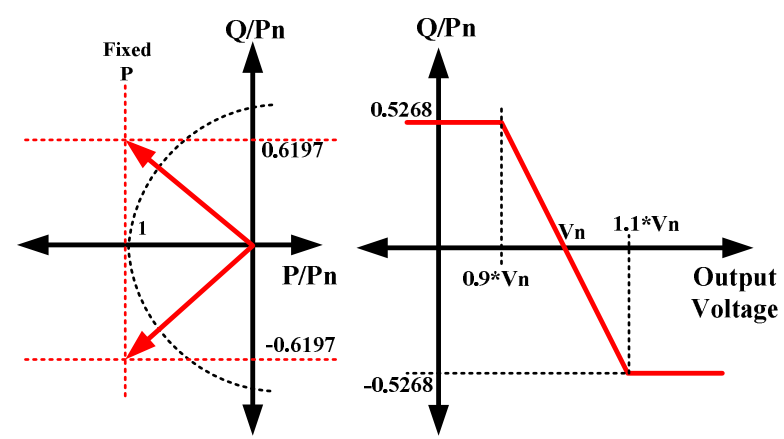

Fig. 3. Reactive power support (static voltage) capability between 0.85 lagging and 0.85 leading.

Fig. 3 can be easily implemented in PSCAD/EMTDC by writing script of Equation 1.

$$
\frac{Q_{r e f}}{P_{n}}=\left\{\begin{aligned}
10 \times\left(\frac{Q}{P_{n}}\right)_{\max } & \left(-\frac{1}{V_{n}} V_{r m s}+1\right), \quad 0.9 V_{n}<V_{r m s}<1.1 V_{n} \\
& \left(\frac{Q}{P_{n}}\right)_{\max }, \quad V_{r m s} \leq 0.9 V_{n} \\
& -\left(\frac{Q}{P_{n}}\right)_{\max }, \quad V_{r m s} \geq 1.1 V_{n}
\end{aligned}\right.
$$

\section{Simulation StUdy AND RESUlts}

\section{A. Benchmark Network Model}

LV network model and its parameters are given in Table I. Single-phase group of fixed loads and PV inverters are connected to the feeder through four nodes with realistic distances (Fig. 4).

TABLE I

BENCHMARK NETWORK PARAMETERS

\begin{tabular}{|c|c|}
\hline MV Grid & $\begin{array}{c}\text { Un=20 kV line-to-line } \\
\text { Sk=200 MVA, R/X=0.5 }\end{array}$ \\
\hline Distribution & $\begin{array}{c}\text { Dyn11, 20/0.4kV, } \\
\text { S=250 kVA, uk=4\% } \\
\text { Transformer }\end{array}$ \\
\hline Cable & NAYY $4 \times 25 \mathrm{~kW}$ \\
& $\begin{array}{c}\mathrm{r}=0.32 \mathrm{ohm} / \mathrm{km} \\
\mathrm{x}=0.082 \mathrm{ohm} / \mathrm{km}\end{array}$ \\
\hline
\end{tabular}

Each RL load is represented as fixed power RL loads. Equivalent resistance and inductance are dynamically updated in such a way that reference values of apparent power and power factor are tracked by measuring terminal voltage. To study voltage rise in the feeder and total power generation 


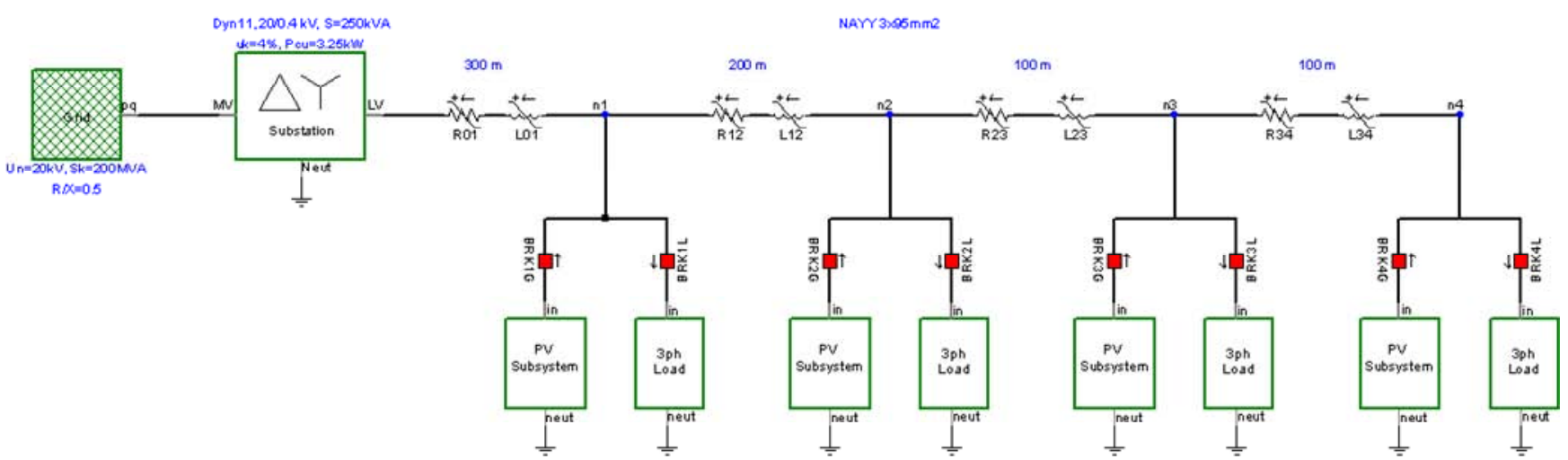

Fig. 4. PSCAD/EMTDC model of LV benchmark distribution network.

efficiency from inverters, switching and network transients are neglected in this paper. Each PV inverter is composed of current source with grid synchronization and voltage control strategies under assumption of fixed PV power and 100\% converter efficiency (Fig. 5).

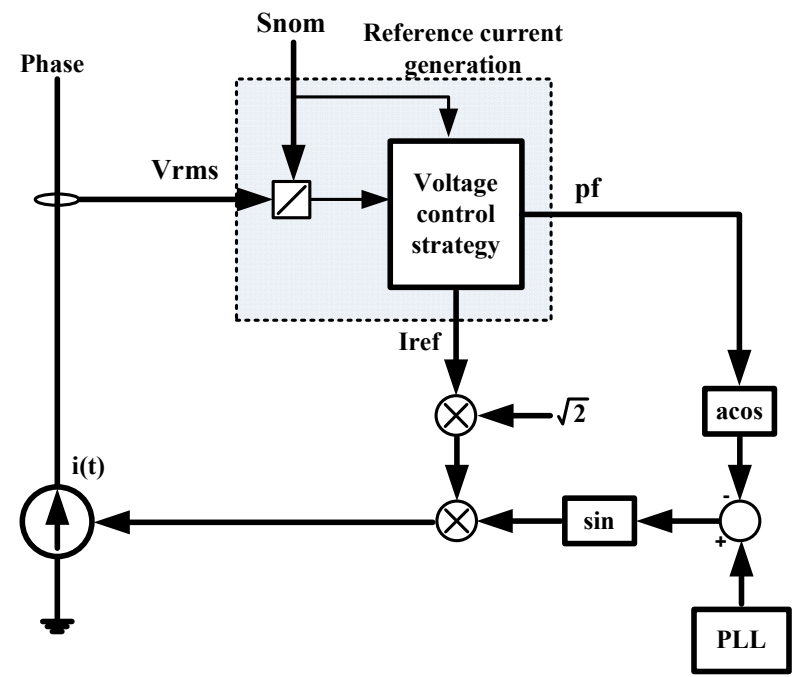

Fig. 5. PV subsystem.

$$
i(t)=\sqrt{2} I_{r e f}(t) \sin [\omega t-\delta-\arccos (p f)]
$$

Equivalent impedances of $20-\mathrm{kV}$ grid and distribution transformer are calculated from given short-circuit capacities to reflect real LV distribution network in the simulation.

To verify operation of distribution network together with loads and PV inverters, feeder voltage profiles without PV and with PV integration are depicted in Fig. 6 under different load profiles and PV penetration levels (Table II). Over voltage condition is created in scenario 3 where inverters are only injecting active power (power factor $=0$ ) and power flows from LV to MV network through distribution transformer.

\section{B. Simulation Results of Power Curtailment and Reactive Power Control}

Two voltage control strategies, power curtailment and reactive power control, are compared in this section. By including additional script of power curtailment into PV subsystem, as shown in Fig. 7, the feeder voltage is forced to stay under $253 \mathrm{~V}$. In this case injected active power into grid is reduced (more than $50 \%$ for node 4 ). The most power reduction occurs at node 4 which has a higher local voltage due to reverse power flow in the feeder (Fig. 8). When the owner of PV generation plants is residential units, power curtailment strategy by itself is not feasible due to unfair power limitation between generators.

TABLE II

Simulated LoAd Profiles AND PENETRATION LEVElS

\begin{tabular}{|c|c|c|}
\hline & Load Profile & Characteristic/each node \\
\hline \multirow{4}{*}{$\begin{array}{l}z \\
\vdots \\
z\end{array}$} & 1 & $12 \mathrm{kVA}, 0.9$ lagging \\
\hline & 2 & $3 \mathrm{kVA}, 0.9$ lagging \\
\hline & 3 & No load \\
\hline & Scenario & Characteristic \\
\hline \multirow{3}{*}{ 焉 } & 1 & $\begin{array}{c}\text { 75\% generation/load ratio with } \\
\text { unity pf (0.9 lagging 48-kVA+36- } \\
\text { kW PV) }\end{array}$ \\
\hline & 2 & $\begin{array}{c}100 \% \text { generation/load ratio with } \\
\text { unity pf ( } 0.9 \text { lagging } 48-\mathrm{kVA}+48 \text { - } \\
\mathrm{kW} \mathrm{PV})\end{array}$ \\
\hline & 3 & $\begin{array}{l}\text { The worst case-overvoltage } \\
\text { condition (No load+180-kW PV) }\end{array}$ \\
\hline
\end{tabular}

In place of power curtailment strategy, reactive power capability between 0.85 leading and 0.85 lagging is added to each inverter model by keeping fixed active power injection (Fig. 9). 15-kW maximum active power generation for each node during simulation is chosen in such a way that 0.85 lagging power factor operation without loads does not cause over voltage issue in the feeder.

Despite higher available power, only $59.72 \%$ of total generation capacity is injected into the feeder to comply with local PCC voltage constraint for power curtailment strategy. Furthermore, as shown in Fig. 8, inverters which are located at node 1 have no contributions to curtailments. In the case of reactive power strategy, more power injection is achieved but reactive power support by inverters are limited. Moreover, additional reactive power flows along the feeder caused by lagging power factor operation of inverters and reactive power transfer losses are also boosted. Alternatively, these two strategies without communication link between inverters can be used together by optimizing active power injection when PCC voltage exceeds limit value. Thus, the operation range 


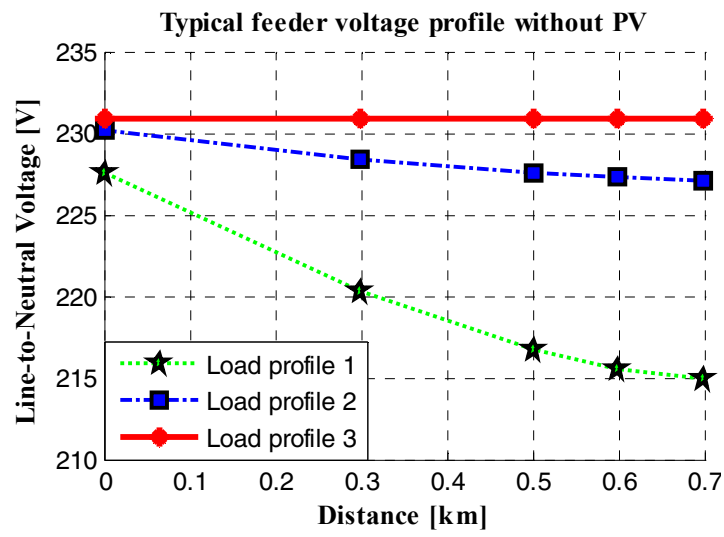

(a)

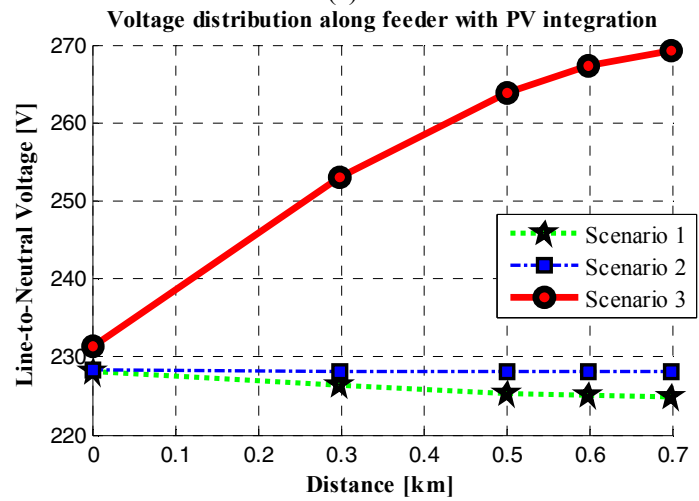

(b)

Fig. 6. Voltage profile (a) without PV, (b) with PV

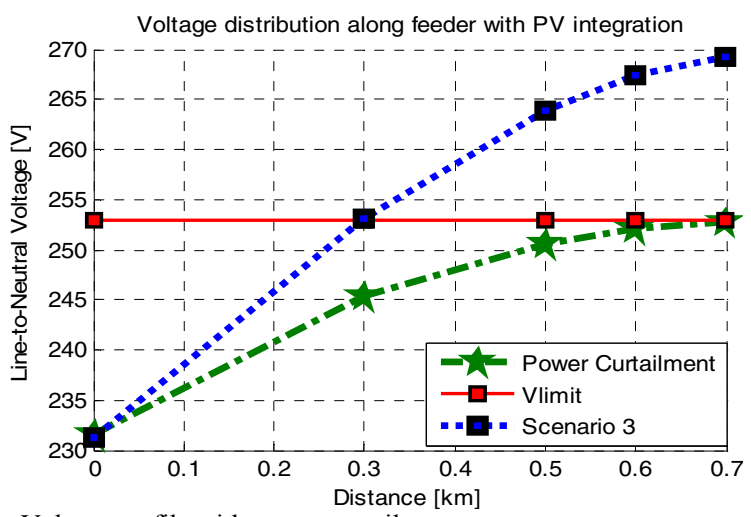

Fig. 7. Voltage profile with power curtailment

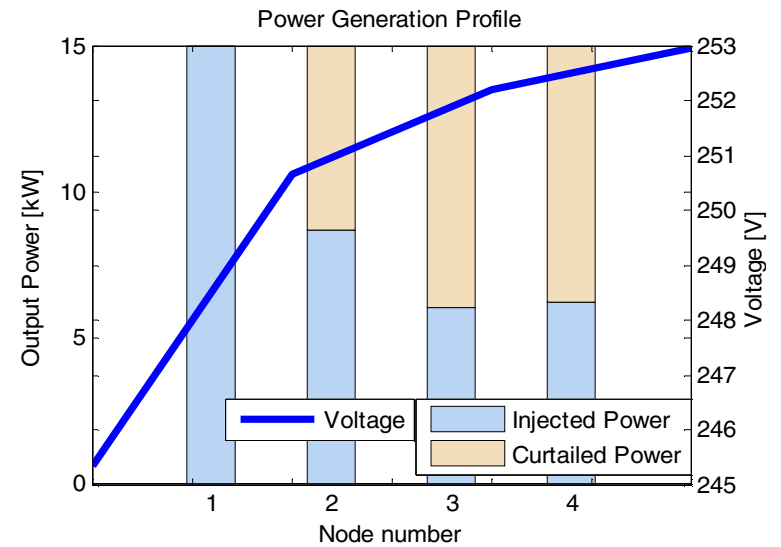

Fig. 8. Active power generation profile of single-phase inverters equipped with power curtailment strategy can be extended efficiently under various $\mathrm{R} / \mathrm{X}$ network impedances.

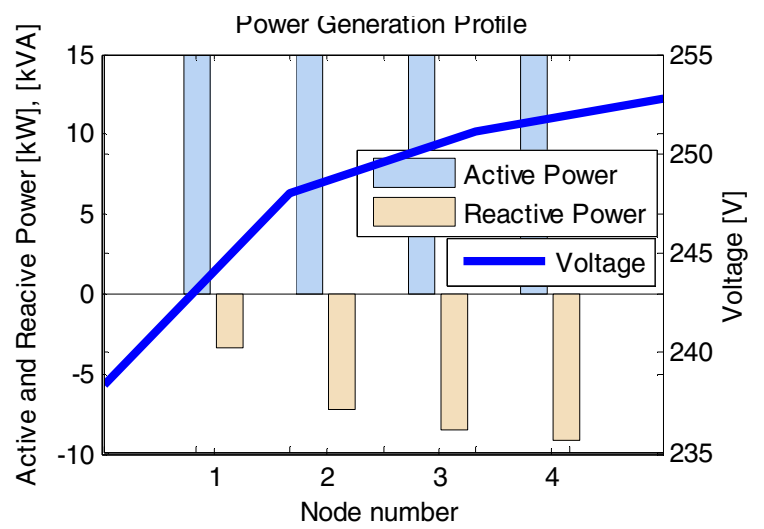

Fig. 9. Active and reactive power generation profile of single-phase inverters equipped with reactive power strategy

\section{CONCLUSION}

Large penetration of $\mathrm{DG}$ in $\mathrm{LV}$ distribution may lead to power quality problems with too high voltage during light load situations. This has been simulated under realistic conditions.

Two possible autonomous strategies which can be implemented in individual inverters have been studied. Power curtailment is one strategy, which can be used to keep the grid voltage within the limits of EN50160. This strategy may lead to a high level of power curtailment with unfair distribution between the single inverters.

As a second strategy, reactive power control improves the level of power delivery, but it is still not efficient method for high value of $\mathrm{R} / \mathrm{X}$ networks and additional inverter size is required to absorb reactive power from the grid.

More intelligent methods should be used for better utilization of the distribution network.

\section{REFERENCES}

[1] Lenardic, D., "Large-scale photovoltaic power plants - Annual and cumulative installed power output capacity key statistical indicators" Annual Review 2008, pvresources.com.

[2] Kimber, A.; Mitchell, L.; Wenger, H., "First year performance of a 10 MWp tracking PV plant in Bavaria Germany" $21^{s t}$ European Photovoltaic Solar Energy Conference, pp. 2695-2699, September 2006.

[3] Almonacid, G.; Perez, P.J.; Vidal, P.G.; Aguilera, J.; Nofuentes, G.; Luque-Heredia, I.; Magalhaes, P.H.; Moreno, J.M.; Quemere, G.; Cervantes, R., "Lorca PV solar park. A large (7MW) PV plant in southeast of Spain. Towards the $2000 \mathrm{kWh} / \mathrm{kWp"} 21^{\text {st }}$ European Photovoltaic Solar Energy Conference, pp. 2777-2781, September 2006.

[4] Morozumi, S.; Nakama, H.; Inoue, N., "Demonstration projects for gridconnection issues in Japan" Elektrotechnik \& Informationstechnik, pp. 426-431, 2008.

[5] Konishi, H.; Tanaka, R.; Shiraki, T., "The Hokuto mega-solar project" Sol. Energy Mater. Sol. Cells (2009), doi:10.1016/j.solmat.2008.12.020

[6] Morozumui, S.; Inoue, N.; Arashiro, Y.; Chiba, Y.; Iwasaki, T., "Strategies and status of grid-connection technology development in NEDO" IEEE Power and Energy Society General Meeting - Conversion and Delivery of Electrical Energy in the 21 $1^{\text {st }}$ Century, pp. 1-6, July 2008.

[7] Laukamp, H.; Thoma, M.; Meyer, T.; Erge, T., "Impact of a large capacity of distributed PV production on the low voltage grid" $19^{s t}$ European Photovoltaic Solar Energy Conference, 2004.

[8] Keizer, C.; Horst, E.; Sark, W., "Performance evaluation of the $1 \mathrm{MW}$ building integrated PV project in Nieuwland, Amersfroot, the Netherlands" PV UP-Scale Project, 2008. 
[9] Teodorescu R.; Blaabjerg, F.; Liserre, M.; Loh, P.C., "Proportionalresonant controllers and filters for grid-connected voltage-source converters" IEE Proceedings Electric Power Applications, vol. 153, pp. 750-762, September 2006.

[10] Timbus, A.V.; Teodorescu R.; Blaabjerg, F.; Borup, U., "ENS detection algorithm and its implementation for PV inverters" IEEE International Symp. on Industrial Electronics, vol. 153, pp. 206-212, March 2006.

[11] Ciobotaru, M.; Agelidis, V.; Teodorescu, R., "Accurate and lessdisturbing active anti-islanding method based on PLL for grid-connected PV inverters" IEEE Power Electronics Specialists Conference, pp. 1481-1487, June 2008.

[12] Rodriguez, P.; Timbus, A.V.; Teodorescu, R.; Liserre, M.; Blaabjerg, F., "Flexible active power control of distributed power generation systems during grid faults" IEEE Transactions on Industrial Electronics, vol. 54, pp. 2583-2592, October 2007.

[13] Wang, F.; Duarte, J.L.; Hendrix, M., "Control of grid-interfacing inverters with integrated voltage unbalance correction" IEEE Power Electronics Specialists Conference, pp. 310-316, June 2008.

[14] Voltage characteristics of electricity supplied by public distribution systems, EN 50160 Standard, 1999.

[15] Requirements for the connection of micro-generators in parallel with public low-voltage distribution networks, EN 50438 Standard, 2007.

[16] Engler, A.; Soultanis, N., "Droop control in LV-grids" International Conference on Future Power Systems, November 2005.

[17] Cipcigan, L.M.; Taylor, P.C., "Investigation of the reverse power flow requirements of high penetrations of small-scale embedded generation", IET Renewable Power Generation, vol. 1, pp. 160-166, September 2007.

[18] Rudion, K.; Styczynski, A.; Hatziargyriou, N.; Papathanassiou, S.; Strunz, K.; Ruhle, O.; Orths, A.; Rozel, B., "Development of benchmarks for low and medium voltage distribution networks with high penetration of dispersed generation", CIGRE Report

[19] , State-of-the art on dispersed PV power generation: Impacts of PVDG and electricity networks. PV-UP-SCALE Project, 2007.

[20] Limit for harmonic current emissions (equipment input current $\leq 16 \mathrm{~A} \mathrm{per}$ phase), EN 61000-3-2 Specification, 2004.

[21] Enslin, J.H.R.; Heskes, P.J.M., "Harmonic interaction between a large number of distributed power inverters and the distribution network" IEEE Transactions on Power Electronics, vol. 19, pp. 1586-1593, November 2004

[22] Mayr, C; Brundlinger, R.; Bletterie, B., "Photovoltaic inverters as active filters to improve power quality in the grid. What can state-of-the-art equipment achieve?" $9^{\text {th }}$ International Conference on Electrical Power Quality and Utilisation, October 2007.

[23] Lee, T.; Cheng, P., "Design of a new cooperative harmonic filtering strategy for distributed generation interface converters in an islanding network" IEEE Transactions on Power Electronics, vol. 22, pp. 19191927, September 2007.

[24] _, DC injection into low voltage AC networks, DTI, 2005

[25] Gertmar, L.; Karlsson, P.; Samuelsson, O., "On DC injection to AC grids from distributed generation" EPE 2005, 2005.

[26] Report IEA-PVPS T5-T10, "Impacts of power penetration from photovoltaic power systems in distribution networks", 2002.

[27] On the connection of photovoltaic installations to the low voltage network, Royal Decree 1663/2000 Standard, 2000.

[28] Salas, V.; Olias, E.; Alonso, M.; Chenlo, F., "Overview of the legistlation of DC injection in the network for low voltage small gridconnected PV systems in Spain and other countries", Renewable and Sustainable Energy Reviews, vol. 12, pp. 575-583, 2008.

[29] IEEE Recommended practice for grid interface of photovoltaic systems, IEEE Standard 929-2000, 2000.

[30] Standard for interconnecting distributed resources with electric power systems, IEEE Standard 1547, 2003.

[31] De Mango, F.; Liserre, M.; Aquila, A.D.; Pigazo, A., "Overview of antiislanding algorithms for PV systems. Part I: Passive methods", $12^{\text {th }}$ International Power Electronics and Motion Control Conference, pp. 1878-1883, September 2006.

[32] De Mango, F.; Liserre, M.; Aquila, A.D., "Overview of anti-islanding algorithms for PV systems. Part II: Active methods", $12^{\text {th }}$ International Power Electronics and Motion Control Conference, pp. 1884-1889, September 2006

[33] Yalcinkaya, G.; Bollen, M.H.J.; Crossley, P.A., "Characterization of voltage sags in industrial distribution systems", IEEE Transactions on Industry Applications, vol. 34, pp. 682-688, July-August 1998.

[34] Bollen, M.H.J.; Olguin, G.; Martins, M., "Voltage dips at the terminals of wind power installations", Nordic Power Conference, March 2004.
[35] Mienski, R.; Pawelek, R.; Wasiak, I.; Gburczyk, P.; Foote, C.; Burt, G.; Espie, P., "Voltage dip compensation in LV networks using distributed energy resources", $11^{\text {th }}$ International Conference on Harmonics and Quality of Power, pp. 774-778, 2004.

[36] Renders, B.; De Gusseme, K.; Ryckaert, W.R.; Stockman, K.; Vandevelde, L.; Bollen, M.H.J., "Distributed generation for mitigating voltage dips in low-voltage distribution grids", IEEE Transactions on Power Delivery, vol. 23, pp. 1581-1588, July 2008.

[37] Bongiorno, M.; Svensson, J., "Voltage dip mitigation using shuntconnected voltage source converter", IEEE Transactions on Power Electronics, vol. 22, pp. 1867-1874, September 2007.

[38] Rodriguez, P.; Timbus, A.V.; Teodorescu, R.; Liserre, M.; Blaabjerg, F., "Independent PQ control for distributed power generation systems under grid faults", $32^{\text {nd }}$ IEEE Annual Conference on Industrial Electronics, pp. 5185-5190, November 2006.

[39] Moreno-Munoz, A.; De La Rosa, J.J., "Analysis of voltage dips in PWM AC-DC converters", International Symposium on Power Electronics, Electrical Drives, Automation and Motion, May 2006.

[40] Liserre, M.; Blaabjerg, F.; Hansen, S., "Design and control of an LCLfilter-based three-phase active rectifier", IEEE Transactions on Industry Applications, vol. 41, pp. 1281-1291, September/October 2005.

[41] Araujo, S.V.; Engler, A.; Antunes, F.L.M., "LCL filter design for gridconnected NPC inverters in offshore wind turbines", The $7^{\text {th }}$ International Conference on Power Electronics, pp. 1133-1138, October 2007.

[42] Tong, Y.; Tang, F.; Chen, Y.; Zhou, F.; Jin, X., "Design algorithm of grid-side LCL-filter for three-phase voltage source pwm rectifier", IEEE Power and Energy Society General Meeting-Conversion and Delivery of Electrical Energy in the 21 $1^{\text {st }}$ Century, pp. 1-6, July 2008.

[43] Liserre, M.; Teodorescu, R.; Blaabjerg, F., "Stability of grid-connected $\mathrm{PV}$ inverters with large grid impedance variation", $35^{\text {th }}$ Annual IEEE Power Electronics Specialists Conference, pp. 4773-4779, 2004.

[44] Liserre, M.; Teodorescu, R.; Blaabjerg, F., "Stability of photovoltaic and wind turbine grid-connected inverters for a large set of grid impedance values", IEEE Transactions on Power Electronics, vol. 21, pp. 263-272, January 2006

[45] Yoshida, K.; Kouchi, K.; Nakanishi, Y.; Ota, H.; Yokoyama, R. "Centralized control of clustered PV generations for loss minimization and power quality", IEEE Power and Energy Society General MeetingConversion and Delivery of Electrical Energy in the $21^{\text {st }}$ Century, pp. 1 6, July 2008.

[46] Conti, S.; Greco, A.M.; Messina, N.; Raiti, S., "Local voltage regulation in LV distribution networks with PV distributed generation", International Symposium on Power Electronics, Electrical Drives, Automation and Motion, pp. 519-524, May 2006.

[47] Bletterie, B; Brundlinger, R., "Laboratory equipment and techniques to validate power electronics-based distributed energy devices", JIEEC 2005 International Electrical Equipment Conference, The Electrical Network of the Future and Distributed Generation, October 2005. 